Document downloaded from:

http://hdl.handle.net/10251/108065

This paper must be cited as:

Cortes-Lopez, V.; Cubero, S.; Aleixos Borrás, MN.; Blasco Ivars, J.; Talens Oliag, P. (2017). Sweet and nonsweet taste discrimination of nectarines using visible and near-infrared spectroscopy. Postharvest Biology and Technology. 133:113-120. doi:10.1016/j.postharvbio.2017.07.015

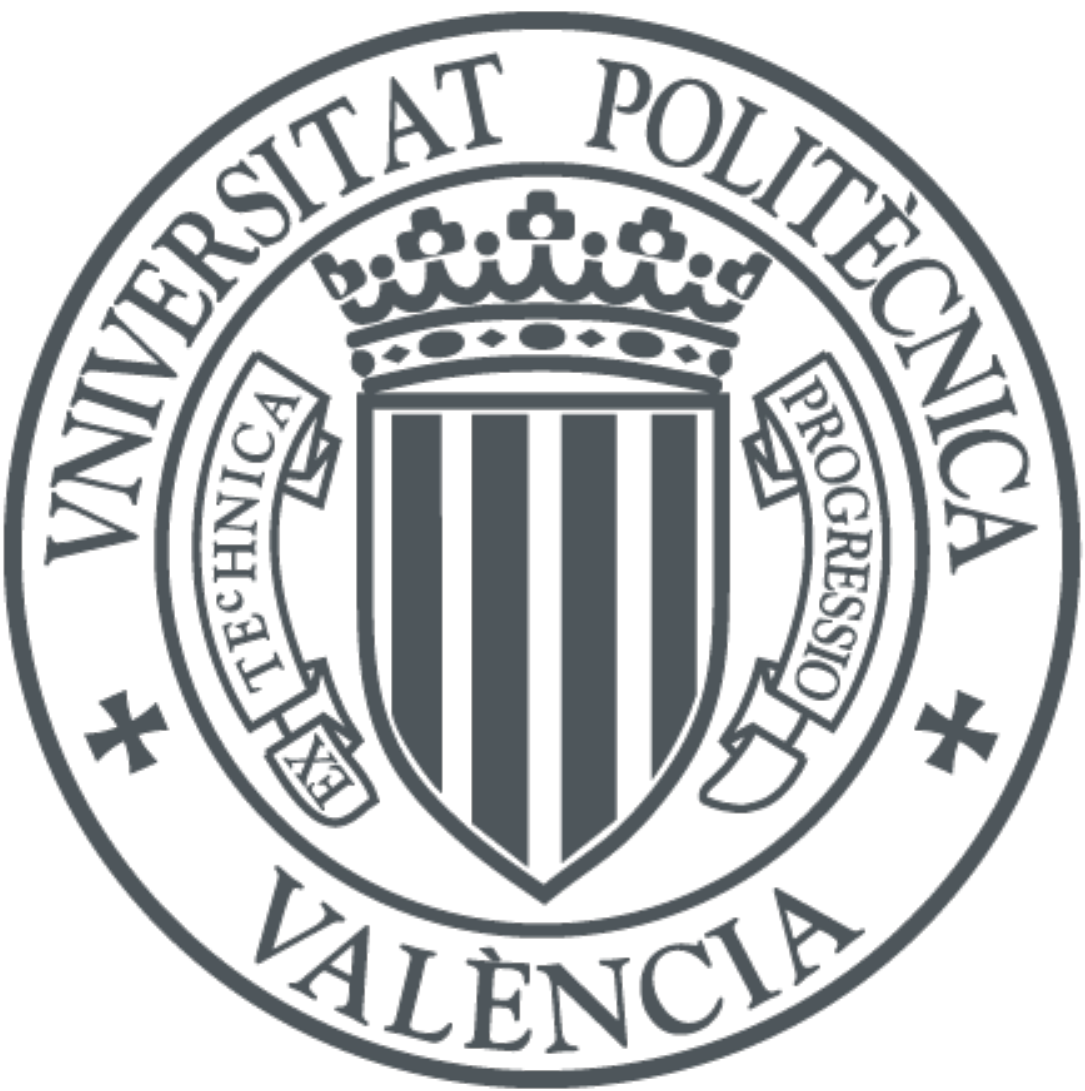

The final publication is available at

https://doi.org/10.1016/j.postharvbio.2017.07.015

Copyright Elsevier

Additional Information 


\title{
Sweet and nonsweet taste discrimination of nectarines using visible and near-
}

\section{infrared spectroscopy}

\author{
Cortés, V. ${ }^{1}$; Cubero, S. ${ }^{2}$; Aleixos, N. ${ }^{3}$; Blasco, J. ${ }^{2}$ Talens, P. ${ }^{1 *}$
}

${ }^{1}$ Departamento de Tecnología de Alimentos. Universitat Politècnica de València.

Camino de Vera s/n, 46022, Valencia (Spain).

${ }^{2}$ Centro de Agroingeniería. Instituto Valenciano de Investigaciones Agrarias (IVIA).

Ctra. CV-315, km 10.7, 46113, Moncada, Valencia (Spain).

${ }^{3}$ Departamento de Ingeniería Gráfica. Universitat Politècnica de València. Camino de Vera s/n, 46022, Valencia (Spain).

*Corresponding author: Pau Talens. Departamento de Tecnología de Alimentos. Universitat Politècnica de València. Camino de Vera, s/n. 46022. Valencia. Spain. Phone: 34-963879836, e-mail: pautalens@tal.upv.es 
ABSTRACT

The feasibility of using visible and near-infrared spectroscopy technology combined with multivariate analysis to discriminate cv. 'Big Top' and cv. 'Diamond Ray' nectarines has been studied. These varieties are very difficult to differentiate visually on the production line but show important differences in taste that affects the acceptance by final consumers. The relationship between the diffuse reflectance spectra and the two nectarine varieties was established. Five hundred nectarine samples (250 of each variety) were used for the study. Tests were performed by using a spectrometer capable of measuring in two different spectral ranges (600 $1100 \mathrm{~nm}$ and $900-1700 \mathrm{~nm})$. These spectral ranges were used to develop two accurate classification models based on linear discriminate analysis (LDA) and partial least squares discriminate analysis (PLS-DA). Later, selection techniques were applied to select the most effective wavelengths. The results showed that the PLSDA model achieved better accuracy and less latent variables than LDA model, and specifically, good results with $100 \%$ classification accuracy were obtained using only the 600 - $1100 \mathrm{~nm}$ spectral range for the two models and eight selected wavelengths. These results places visible and near-infrared spectrocopy as an accurate classification tool for nectarine varieties with a very similar appearance but different tastes that could be potentially used in an automated inspection system.

Keywords: nectarine, sweet taste, nonsweet taste, visible and near-infraed spectroscopy, discrimination, chemometrics

\section{INTRODUCTION}


Nectarine and peach fruit [Prunus persica (L.) Batch] are the second most important fruit crop in the European Union (EU) after apple (Iglesias \& Echeverría, 2009). Recently, significant innovations have been made in the field of fruit varieties that seek improvements in colour and size, consistency of pulp, texture, taste and flavour (Jha et al., 2012; Jha et al., 2006; Picha, 2006; Jha et al., 2005; Jha et al., 2004). New varieties obtained show an attractive range of colours, tastes and forms as well as having an extended maturity schedule, which have given rise to excellent acceptance by consumers in both national and international markets (Iglesias, 2013; Iglesias \& Casals, 2014).

The most appreciated attributes among fruit consumers have been described as being taste, food safety (absence of pesticides), ease of consumption and cost (Wandel \& Bugge, 1997; Radman, 2005; Dragsted, 2008). Regarding taste consumers generally prefer sweet and balanced tastes, except in some countries like Germany or England, where there is preference for nonsweet tastes (Cembalo et al., from in processing line, which would allow the consumer to choose the ones that best 
The application of visible and near-infrared spectroscopy for the analysis of fruit has allowed the prediction of chemical composition, notably sugar content (Li et al., 2013; Reita et al., 2008), and textural parameters (Lee et al., 2012; Sánchez et al., 2011), as well as the identification of varieties (Li et al., 2016; Guo et al., 2016) and the measurement of quality-related parameters (Pérez-Marín et al., 2011). This technique is relatively rapid, simple, cost-effective, non-destructive, and environmentally friendly. Its application in combination with chemometrics has been successfully used in non-destructive discrimination between varieties of agricultural products such as peach (Guo et al., 2016), bayberry (Li et al., 2007), orange (Suphamitmongkol et al., 2013), and pummelos (Li et al., 2016).

This study aimed to evaluate the ability of visible and near-infrared spectroscopy to discriminate between two varieties of nectarine (cv. 'Big Top' and cv. 'Diamond Ray'), which, because there are similar in colour and appearance, are very difficult to differentiate visually on the production line but show important differences in taste, thereby affecting the acceptance by the final consumers. Two supervised methods such as linear discriminate analysis (LDA) and partial least squares discriminate analysis (PLS-DA) were used for this purpose.

\section{MATERIALS AND METHODS}

\subsection{Experimental procedure}

A total of 500 nectarines with commercial maturity and uniform size and the absence of any external damage were harvested in a commercial orchard in Lérida, Spain. They were then stored at $0.1{ }^{\circ} \mathrm{C}$ with $87 \%$ relative humidity to prevent the evolution of maturity during the experiment and to extend their shelf-life (Gorny et al., 1998). Half of the total samples belonged to the variety 'Big Top' and the other half to the 
variety 'Diamond Ray'. These varieties were selected because they are grown in the same period and have a similar evolution and physical appearance, although they differ critically in some of their organoleptic properties.

On arrival at the laboratory, fruits were cleaned, individually numbered and each variety was randomly divided into five sets of 50 fruits. The visible and near-infraed spectra of the fruits in each set were collected and their physicochemical properties (soluble solids, firmness and flesh and external colour) were analysed by standard destructive methods (Cortés et al., 2016; Martins et al., 2016; Li et al., 2013; Hernández et al., 2006).

\subsection{Visible and near-infrared spectra acquisition}

Diffuse visible and near-infraed reflectance spectra of intact nectarines were collected using a multichannel spectrometer platform (AvaSpecAS-5216 USB2-DT, Avantes BV, The Netherlands) equipped with two detectors. The first detector (AvaSpec-ULS2048 StarLine, Avantes BV, The Netherlands) included a 2048-pixel charge-coupled device (CCD) sensor (SONY ILX554, SONY Corp., Japan), $50 \mu \mathrm{m}$ entrance slit and a 600 line mm-1 diffraction grating covering the visible and nearinfrared range from $600 \mathrm{~nm}$ to $1100 \mathrm{~nm}$ (VNIR) with a spectral FWHM (full width at half maximum) resolution of $1.15 \mathrm{~nm}$ and a spectral sampling interval of $0.255 \mathrm{~nm}$. The second detector (AvaSpec-NIR256-1.7 NIRLine, Avantes BV, The Netherlands) was equipped with a 256 pixel non-cooled InGaAs (Indium Gallium Arsenide) sensor (Hamamatsu 92xx, Hamamatsu Photonics K.K., Japan), with a $100 \mu \mathrm{m}$ entrance slit and a 200 line mm-1 diffraction grating covering the near-infrared range from $900 \mathrm{~nm}$ to $1700 \mathrm{~nm}$ (NIR) with a spectral FWHM resolution of $12 \mathrm{~nm}$ and a spectral sampling interval of $3.535 \mathrm{~nm}$. 
125 The measurements were performed using a bi-directional fibre-optic reflectance 126 probe (FCR-7IR200-2-45-ME, Avantes BV, The Netherlands). The probe was 127 configured fitted with an illumination leg which connects to a stabilised $10 \mathrm{~W}$ tungsten halogen light source (AvaLight-HAL-S, Avantes BOV, The Netherlands) and the other 129 leg of the fibre-optic probe was connected to both detectors for simultaneous 130 measurement. A personal computer equipped with software (AvaSoft version 7.2, 131 Avantes, Inc.) was used to control both detectors and to acquire the spectra. The integration times were adjusted for each spectrophotometer using a $99 \%$ reflective white reference tile (WS-2, Avantes BV, The Netherlands), so that the maximum reflectance value over each wavelength range was around $90 \%$ of saturation (Lorente et al., 2015). The white reference tile for reflectance measurements was a $32 \mathrm{~mm}$ diameter and $10 \mathrm{~mm}$ thick block of white polytetrafluoroethylene (PTFE). The white reference tile was placed at a distance of $5 \mathrm{~mm}$ from the probe to make a reference measurement. The dark spectrum was obtained by turning off the light source and completely covering the tip of the reflectance probe. The integration time was set to $120 \mathrm{~ms}$ for the VNIR detector and $550 \mathrm{~ms}$ for the NIR detector due to the different features of the two detectors. For both detectors, each spectrum was obtained as the average of five scans to reduce the thermal noise of the detector (Nicolaï et al., 2007). The average reflectance measurements of each sample (S) were then converted into relative reflectance values $(R)$ with respect to the white reference using dark reflectance values (D) and the reflectance values of the white reference $(W)$, as shown in Eq. (1):

$$
R=\frac{S-D}{W-D}
$$


150 Prior to the spectral measurements, the temperature of the nectarines was stabilised

151 at a room temperature of $22 \pm 1{ }^{\circ} \mathrm{C}$. All the measurements were taken at two points

152 on each side of the fruit and mean values of the spectra were used for the analysis.

\subsection{Determination of the quality attributes}

Destructive methods were performed immediately after the spectral acquisition to determine the quality attributes for use as reference values. Both the external and the flesh colours were measured using a spectrocolorimeter (CM-700d, Minolta Co., Tokyo, Japan) every $10 \mathrm{~nm}$ between 400 and $700 \mathrm{~nm}$. The colour was evaluated using the $L^{*}, a^{*}$ and $b^{*}$ space proposed by the International Commission on Illumination (CIE). $L^{*} a^{*} b^{\star}$ were determined from the reflectance spectra, considering standard illuminant D65 and standard observer $10^{\circ} . \mathrm{L}^{*}$ refers to the luminosity or lightness component, $\mathrm{a}^{\star}$ (intensity of red $(+)$ and green $(-)$ ) and b* (intensity of yellow

$(+)$ and blue $(-))$ are the chromaticity coordinates. The total colour difference $(\Delta E)$ between the 'Big Top' samples and the 'Diamond Ray' samples was calculated by Eq. (2).

$$
\Delta \mathrm{E}=\sqrt{\left(L^{*}{ }_{B T}-L^{*}{ }_{D R}\right)^{2}+\left(a^{*}{ }_{B T}-a^{*}{ }_{D R}\right)^{2}+\left(b^{*}{ }_{B T}-b^{*}{ }_{D R}\right)^{2}}
$$

where subscript 'BT' refers to the colour reading of the 'Big Top' samples and 'DR' refers to the colour reading of the 'Diamond Ray' samples.

171 Nectarine firmness was measured using a Universal Testing Machine 172 (TextureAnalyser-XT2, Stable MicroSystems, Haslemere, England) to perform puncture tests using a $6 \mathrm{~mm}$ diameter cylindrical probe (P/15ANAMEsignature) to a 
175 performed for each fruit on opposite sides along the equator. The fracture strength 176 ( $\left.F_{\max }\right)$ was analysed for all samples as the maximum force applied to break up the sample, being expressed in Newtons. Immediately after firmness measurements, juice samples were extracted to estimate the total soluble solids content (TSS) and titratable acidity (TA). The TSS was determined by refractometry (\%) with a digital refractometer (set RFM330+, VWR International Eurolab S.L Barcelona, Spain) at $20{ }^{\circ} \mathrm{C}$ with a sensitivity of $\pm 0.1 \%$. Samples were analysed in triplicate and average values were calculated. The analysis of the TA was performed with an automatic titrator (CRISON, pH-burette 24, Barcelona, Spain) with $0.5 \mathrm{~N} \mathrm{NaOH}$ until a $\mathrm{pH}$ of 8.1 (UNE34211:1981), using $15 \mathrm{~g}$ of crushed nectarine, which was diluted in $60 \mathrm{~mL}$ of distilled water. The TA was determined based on the percentage of citric acid, which was calculated using Eq. (3).

where $\mathrm{A}$ is the volume of $\mathrm{NaOH}$ consumed in the titration (in $\mathrm{L}$ ), $\mathrm{B}$ is the normality of $\mathrm{NaOH}(0.5 \mathrm{~N}), \mathrm{C}$ is the molecular weight of citric acid (192.1 $\mathrm{g} \mathrm{mol}-1), \mathrm{D}$ is the weight of the sample $(15 \mathrm{~g})$ and $E$ is the valence of citric acid $(E=3)$.

\subsection{Spectral pre-processing}

The spectral data were organised in a matrix, where the rows represent the number of samples (\#N = 500 samples) and the columns represent the variables (X-variables and $\mathrm{Y}$-variables). The $\mathrm{X}$-variables, or predictors, were the spectral signals from the two detectors. The Y-variables, or responses, were the artificial (dummy) variables 
created by assigning different values or letters to the different classes to be discriminated. In the case of PLS-DA, assuming a discrete numerical value (zero for the cv. 'Diamond Ray' or one for the cv. 'Big Top'), was used as Y-variable. However, for LDA the Y-variable was a categorical value created by assigning different letter to the different cultivar ( $A$ for the $\mathrm{cv}$. 'Diamond Ray' and $B$ for the cv. 'Big Top'). In addition, for LDA the number of samples in the training set must be larger than the number of variables included in the model (Kozak \& Scaman, 2008; Sádecká et al., 2016), thus requiring a variable selection or variable reduction. This was performed using the principal component analysis (PCA) scores as input data, since the linear combinations of the original variables, called principal components, are uncorrelated (Rodríguez-Campos et al., 2011).

211 The raw spectra were transformed to apparent absorbance (log $(1 / R))$ values so as to 212 be able to linearise the correlation with the concentration of the constituents (Hernández et al., 2006; Shao et al., 2007; Liu et al., 2009) using The Unscrambler X software package (CAMO, Norway). Then, the raw spectra belonging to the two detectors were normalised (Bakeev, 2010) by dividing each variable by its standard deviation (Bouveresse et al., 1996). By so doing, the spectral intensities are rescaled to a common range, thus allowing the comparison of spectra acquired using two detectors with different resolutions.

In addition, different pre-processing techniques were applied. Savitzky-Golay smoothing with a gap of three data points (Carr et al., 2005) was applied to improve the signal-to-noise ratio in order to reduce the effects caused by the physiological variability of samples (Carr et al., 2005; Beghi et al., 2017). Due to the fresh light scattering in samples (Gelbukh et al., 2006), the light does not always travel the same distance in the sample before it is detected. A longer light traveling path 
corresponds to a lower relative reflectance value, since more light is absorbed. This causes a parallel translation of the spectra. This kind of variation inteferes in the calibration models and need to be eliminated by the extend multiplicative scatter correction (EMSC) technique (He et al., 2007; Martens et al., 2003; Bruun et al., 2007). In addition to those two pre-processing, the second derivate with GapSegment (2.3) were applied for the NIR spectra because it allowed the extraction of useful information (Cortés et al., 2016; Rodriguez-Saona et al., 2001).

\subsection{Multivariate data analysis of spectral data}

PCA (Naes et al., 2004), PLS-DA and LDA were used in this work by means of The Unscrambler $X$ software package. PCA was selected as the method for outlier detection (through the analysis of Hotelling's T2 and squared residual statistics) and to explore the data structure and the relationship between objects (Beghi et al., 2017; Beebe et al., 1998), in order to pinpoint the most relevant varietal groups and spectral features. So, the use of suitable projection, e.g., PCA or partial least square regression (PLS) (Balabin et al., 2007; Xiabo et al., 2010) may help to minimize the large number of spectral variables in the data sets and identify variables that contribute useful information (effective wavelengths, EWs). In this study, wavelengths with large loading weight values were selected as important for the varietal discrimination. EWs were selected as only those located at the peaks or valleys of $x$ loading weights plots, and with an absolute x-loading weight higher than 0.1 (Liu et al., 2008).

PLS-DA and LDA were used to classify the nectarines in terms of variety. These discriminant analyses seek to correlate spectral variations $(X)$ with defined classes $(\mathrm{Y})$, attempting to maximise the covariance between the two types of variables. 
250 A training set was used and consisted in randomly selecting $80 \%$ of the samples that

251

252

253

254

255

256

257

258

259

260

261

262

263

264

265

266

267

268

269

270

271

272

273

274

were studied to develop a calibration model. Each calibration model was internally validated using the leave-one-out cross-validation technique (Huang et al., 2008). In order to correct the relative influences of the different instrumental responses on a model, a standardisation technique was used, where the weight of each X-variable was the standard deviation of the variable (Bouveresse et al., 1996). An independent test set composed of the remaining $20 \%$ of the samples was used for the evaluation and comparison of the classification models (Soares et al., 2013).

\subsection{Model performance evaluation}

The PLS-DA cut-off value for nectarine samples discrimination was fixed at 0.5 . If the predicted value of a sample was less than 0.5 , the sample was assigned to the group of the 'Diamond Ray' samples, while if the predicted value was more than 0.5 , the sample was assigned to the group of the 'Big Top' samples. The determination coefficient $\left(R^{2}\right)$, root mean square error (RMSE) and the number of latent variables (LVs) were used to evaluate the accuracy of the PLS-DA calibration model to predict new samples. In the case of LDA, the criterion for the selection of LVs is maximum differentiation between the categories and minimal variance within categories (Cardoso \& Silva, 2016; Naes et al., 2002; Adams, 1995). The method produces a number of orthogonal linear discriminant functions, equal to the number of categories minus one, that allow the samples to be classified in one category or another (Naes et al., 2002; Otto, 1999).

\section{RESULTS AND DISCUSSION}

\subsection{Analysis of the quality attributes}


275 Table 1 shows the minimum, maximum, mean and standard deviation of the 276 physicochemical characteristics (fracture strength, total soluble solids, tritatable 277 acidity, and flesh and external colour) analysed in the samples of both varieties of 278 nectarines (\#N = 250 samples for each variety).

279

280 Table 1. Descriptive statistics for the physicochemical characteristics of nectarines 281 during the storage period

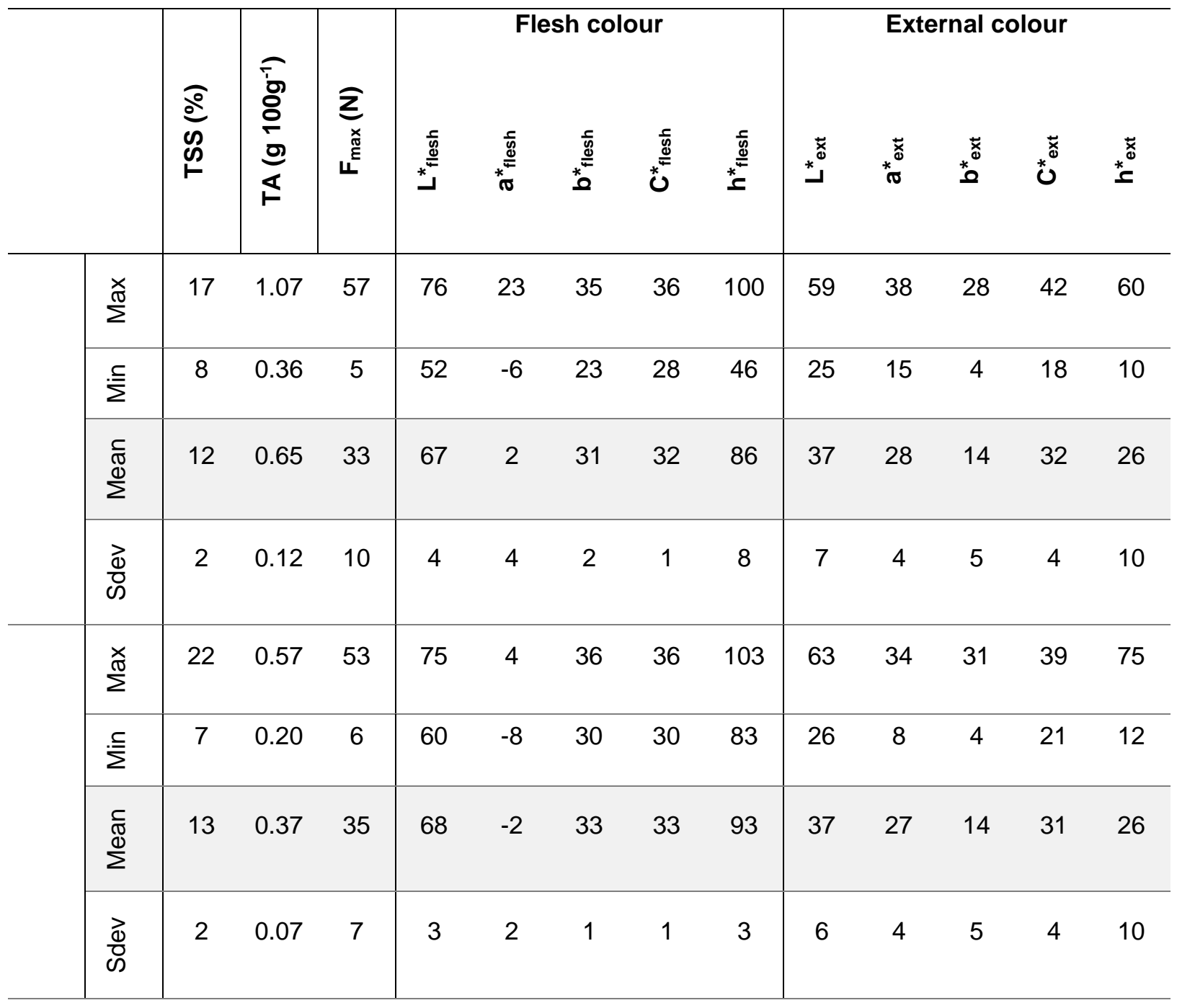

283 No differences were observed between the two varieties, and among the different 284 sets, in terms of soluble solids, firmness, and flesh and external colour. 
285

286

287

288

289

290

291

292

293

294

295

296

297

298

299

300

301

302

303

304

305

306

307

308

309

The TSS ranged from 8 to $17 \%$ with an average value of $12 \pm 2 \%$ for cv. 'Diamond Ray' and from 7 to $22 \%$ with an average value of $13 \pm 2 \%$ for cv. 'Big Top'. In all cases, the values of TSS were greater than $8 \%$, which is the minimum established by the European Union to market peaches and nectarines (R-CE No. 1861/2004). Several authors have reported a linear relationship between TSS and consumer acceptance (Crisosto \& Crisosto, 2005), a TSS below $10 \%$ generally being unacceptable to consumers (Clareton, 2000).

The firmness of 'Diamond Ray' samples ranged from 5 to $57 \mathrm{~N}$ with an average value of $33 \pm 10 \mathrm{~N}$, and 'Big Top' samples ranged from 6 to $53 \mathrm{~N}$ with an average value of $35 \pm 7$ N. According to Crisosto (2002) and Valero et al. (2007), these firmness values are in the commercial range considered 'ready to buy'.

For flesh colour, $L^{*}, a^{*}, b^{\star}, C^{*}$ and $h^{\star}$ ranged from 52 to $76,-6$ to 23,23 to 35,28 to 36 and 46 to 100 for cv. 'Diamond Ray' and from 60 to $75,-8$ to 4,30 to 36,30 to 36 and 83 to 105 for cv. 'Big Top', with average values of $67 \pm 4,2 \pm 4,31 \pm 2,32 \pm 1$, $86 \pm 8$ and $68 \pm 3,-2 \pm 2,33 \pm 1,33 \pm 1,93 \pm 3$ respectively. These values indicated that the flesh of both varieties has a high luminosity, low chroma and yellow hue. No differences were observed in luminosity and chroma between sets and between varieties, whereas slight differences in hue were observed between varieties. Despite these differences, the overall perception of flesh colour would make it very difficult to discriminate both varieties, especially during any industrial process where fruits must be inspected quickly, as shown in the images in Figure 1 with examples of each of the sets analysed. According to ISO $12647-2$, colour differences $(\Delta E)$ lower than \pm 5 units make the human eye unable to discriminate two samples. In this case, the $\Delta \mathrm{E}$ between both varieties measured with the colorimeter was \pm 4.5 . Furthermore, differentiating nectarine varieties by the flesh colour requires the destruction of the 
sample, and therefore this destructive analysis results in high costs and does not allow the whole production to be analysed (Torres et al., 2013).

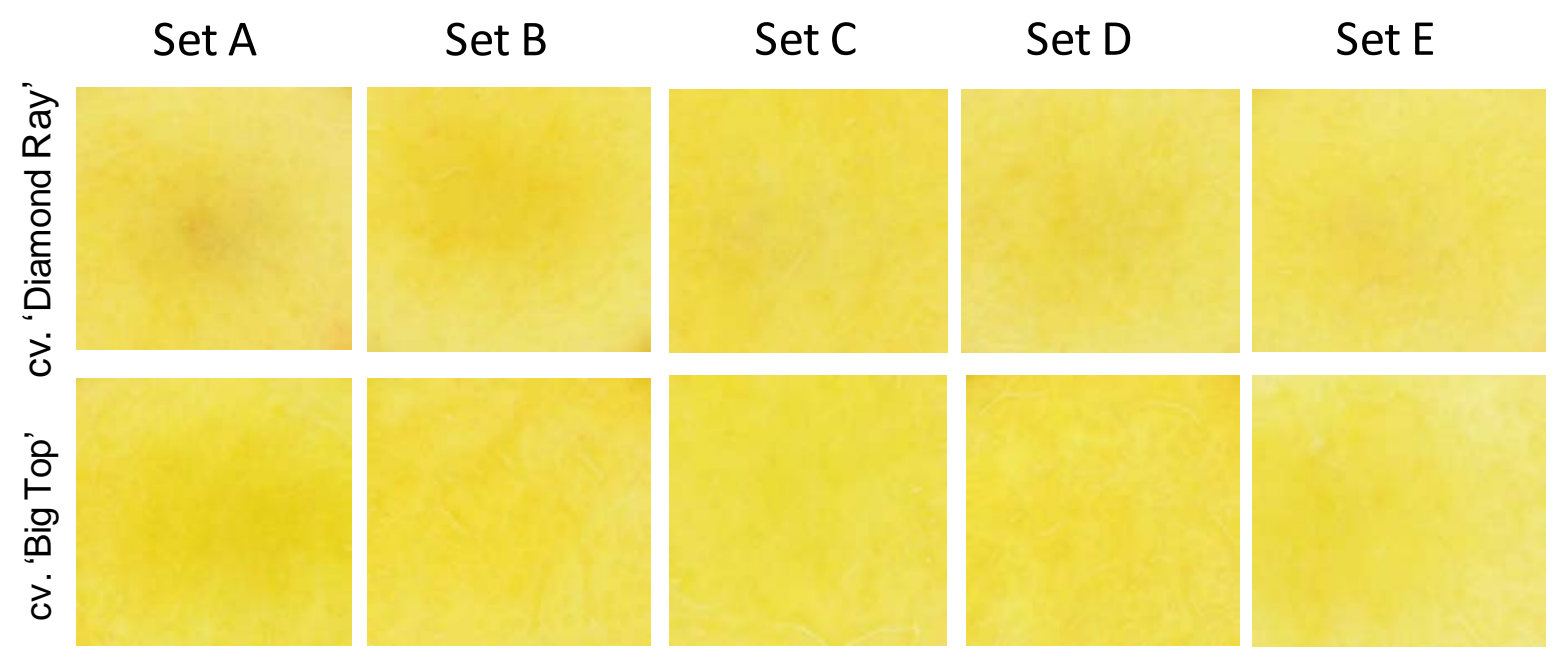

Fig. 1. Example of the internal appearance of both cultivars on each day of analysis.

Regarding the external colour of the nectarines, no significant differences were found in the values of luminosity, chroma and hue for the sets and the varieties studied. The $L^{*}, a^{*}, b^{*}, C^{*}$ and $h^{*}$ ranged from 25 to 59,15 to 38,4 to 28,18 to 42 and 10 to 60 for cv. 'Diamond Ray' and from 26 to 63,8 to 34,4 to 31,21 to 39 and 12 to 75 for cv. 'Big Top', with average values of 37 for luminosity, 31.3 for chroma and $25.9^{\circ}$ for hue, for both varieties. These values indicated that, externally, both varieties had low luminosity, low chroma and red-orange hue. The $\Delta \mathrm{E}$ of external colour between varieties was 1.5, and therefore barely perceptible. Hence, this non-destructive analysis was not valid for varietal discrimination.

The main difference between the two varieties of nectarine was TA, the 'Diamond Ray' variety being more acid than the 'Big Top' variety or, according to the definition of Reig et al. (2013), the are a nonsweet and sweet variety, respectively. All sets of

327 the cv. 'Diamond Ray' had an average value of $0.65 \pm 0.1 \mathrm{~g} 100 \mathrm{~g}-1$, unlike the average value of the sets of the cv. 'Big Top' which was $0.37 \pm 0.1 \mathrm{~g} 100 \mathrm{~g}-1$. These 
results are in accordance with the sensorial profile performed by Iglesias (2012). The study concluded that the only difference between these two varieties is in the perception of acidity. Similarly, Reig et al. (2013) and Liverani et al. (2002) compared sweet cultivars (such as 'Big Top', 'Gardeta' and 'Luciana') with nonsweet cultivars (such as 'Diamond Ray', 'Amiga' and 'Rose Diamond'), and determined that they differed mainly in their TA value and the perception of acidity, the rest of their physicochemical characteristics being similar among the cultivars.

\subsection{Visible and Near-infrared spectra of the two nectarine varieties}

Figure 2 represents the mean raw VNIR and NIR spectra for the 'Diamond Ray' and 'Big Top' samples at different sets of analysis. The trend and absorbance bands of the spectral curves were similar. Previous studies have documented similar values (Pérez-Marín et al., 2009; Pérez-Marín et al., 2011; Martins et al., 2016). The varieties analysed showed the same absorbance bands around $670 \mathrm{~nm}, 970 \mathrm{~nm}$, $1160 \mathrm{~nm}$ and $1450 \mathrm{~nm}$. Authors such as Tijskens et al. (2007) confirmed that the absorption at $670 \mathrm{~nm}$ allowed the maturity of nectarine to be evaluated because it is indicative of the presence of chlorophyll, with its characteristic green colour (Merzlyak et al., 2003; Hernández et al., 2006). The peak centred at $970 \mathrm{~nm}$ is present in the signal recorded by the two detectors. This peak and the one present at $1450 \mathrm{~nm}$ are related to pure water (Williams \& Norris, 1987; McGlone \& Kawano, 1998). A characteristic absorption band at around $1160 \mathrm{~nm}$ related to second overtone $\mathrm{C}-\mathrm{H}$ stretching (Osborne et al., 1993; Walsh et al., 2004). 


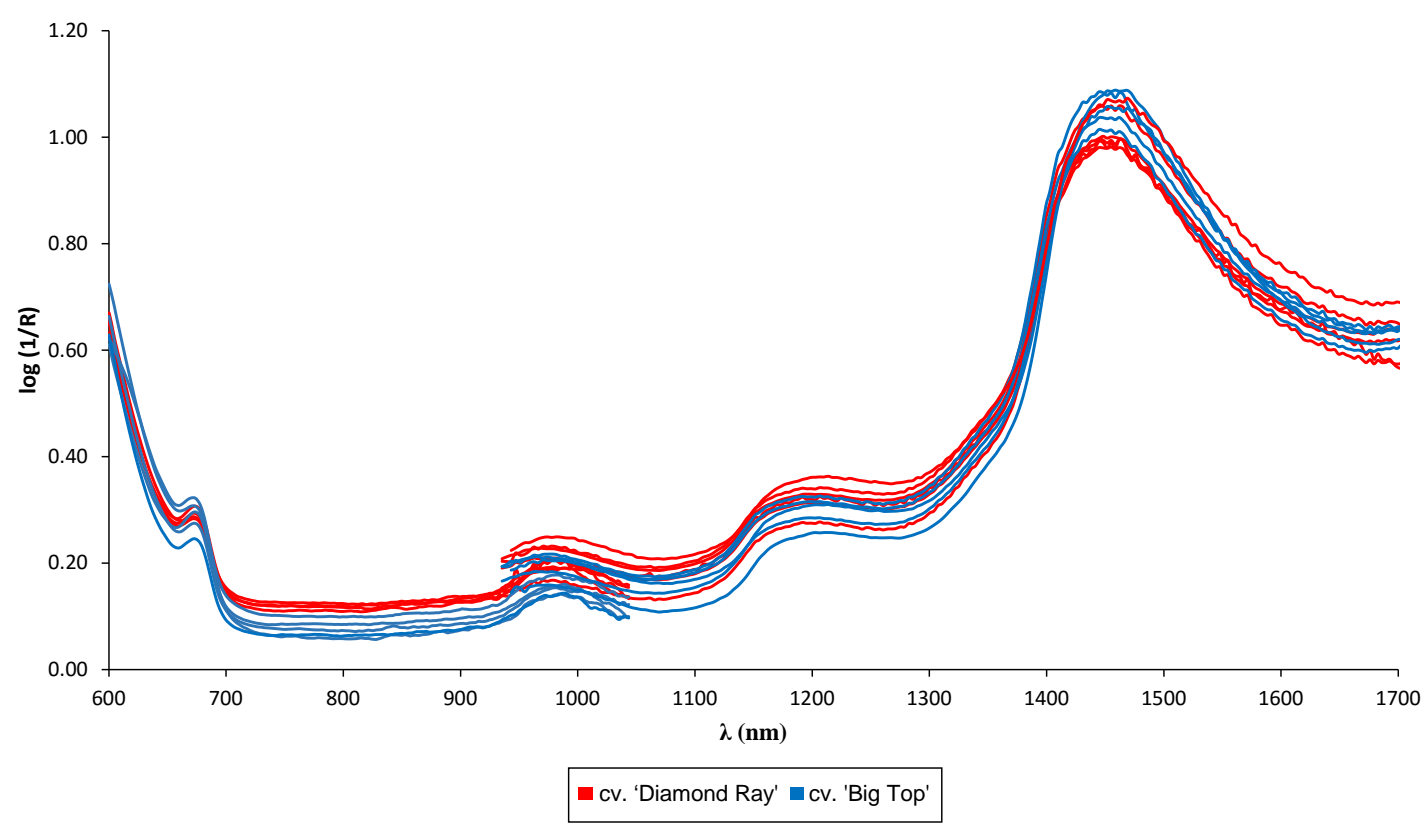

Fig. 2. Averaged raw VNIR and NIR spectra for the two varieties of nectarines at different sets of analysis.

\subsection{Varietal classification}

Classification models were built based on supervised PLS-DA and LDA with the full spectral range, with only the VNIR and NIR spectral ranges separately, and with the effective wavelengths selected (EWs) from the original ranges. Table 2 shows the predictive ability for each validation set for the twelve models developed. Similar results were obtained to PLS-DA models for each spectral ranges and with the most important EWs. However, the LDA models were less accurate with higher number of LV and EWs than PLS-DA models. The optimal number of LVs was chosen according to the lowest RMSE cross-validation (RMSECV) by internal validation using the leave-one-out cross validation technique, in combined analysis with the cumulative variance in the $X$ and $Y$ blocks (Bachion de Santana et al., 2016). The $x$ loading weights obtained for the different spectral ranges with only the EWs selected are shown in Figure 3. 
Table 2. Varietal classification results for each methods, presented both as a percentage and an absolute number of correctly classified samples in the validation sets.

\section{Classification accuracy}

\begin{tabular}{|c|c|c|c|c|c|c|}
\hline \multirow[t]{2}{*}{ Methods } & & \multirow{2}{*}{ EWs } & \multirow{2}{*}{ LVs } & \multicolumn{2}{|l|}{ cV. } & \multirow{2}{*}{$\begin{array}{c}\text { Total } \\
\text { samples }\end{array}$} \\
\hline & & & & 'Diamond Ray' & 'Big Top' & \\
\hline \multirow[t]{6}{*}{ PLS-DA } & Full & 2189 & 5 & $100 \%(50 / 50)$ & $100 \%(50 / 50)$ & $100 \%$ \\
\hline & & 12 & 4 & $94 \%(47 / 50)$ & 86 \% (43/50) & $90 \%$ \\
\hline & VNIR & 1838 & 6 & $100 \%(50 / 50)$ & $100 \%(50 / 50)$ & $100 \%$ \\
\hline & & 8 & 5 & $100 \%(50 / 50)$ & $100 \%(50 / 50)$ & $100 \%$ \\
\hline & NIR & 213 & 8 & $100 \%(50 / 50)$ & $100 \%(50 / 50)$ & $100 \%$ \\
\hline & & 7 & 4 & $92 \%(46 / 50)$ & $98 \%$ (49/50) & $95 \%$ \\
\hline \multirow[t]{6}{*}{ LDA } & Full & 2189 & 14 & $100 \%(50 / 50)$ & $100 \%(50 / 50)$ & $100 \%$ \\
\hline & & 12 & 10 & $94 \%$ (47/50) & 86 \% (43/50) & $90 \%$ \\
\hline & VNIR & 1838 & 12 & 98 \% (49/50) & $100 \%(50 / 50)$ & $99 \%$ \\
\hline & & 8 & 7 & $100 \%(50 / 50)$ & $100 \%(50 / 50)$ & $100 \%$ \\
\hline & NIR & 213 & 5 & 84 \% (42/50) & 76 \% (38/50) & $80 \%$ \\
\hline & & 7 & 6 & $98 \%(49 / 50)$ & $96 \%(48 / 50)$ & $97 \%$ \\
\hline
\end{tabular}

375 Using all 2189 spectrum features, PLS-DA and LDA achieved external validation 376 accuracies of $100 \%$. Selecting 12 wavelenghts, PLS-DA and LDA achieved 377 classification accuracy of $90 \%$ with four and ten LVs, respectively. PLS-DA was able 
378 to correctly classify all samples in the validation set by using the 213 wavelengths of

379 NIR detector and with only seven EWs and four LVs attained $95 \%$, although LDA 380 achieved better results with only seven EWs and six LVs (97\% of accuracy) than 381 with all wavelengths of the NIR detector (80\% of accuracy). However, selecting only 382 eight EWs out 1838 available features of VNIR detector, PLS-DA and LDA model 383 attained $100 \%$ validation accuracies with five and seven LVs, respectively. These 384 eight EWs were selected including 648, 883, 949, 1006, 1025, 1026, 1037, and 1054 nm. So, with only these eight EWs obtained by VNIR detector was possible achieved better accuracy classification results (100 \%) than the other models developed with the other spectral ranges. An explanation for this result would be that visible spectroscopy is more suitable for the characterization of nectarine colours, which are very similar in both varieties, while near infrared spectra provides complementary 390 information (Liu et al., 2003) related to the macronutrients and the interactions that they can develop with other constituents (Lucas et al., 2008).

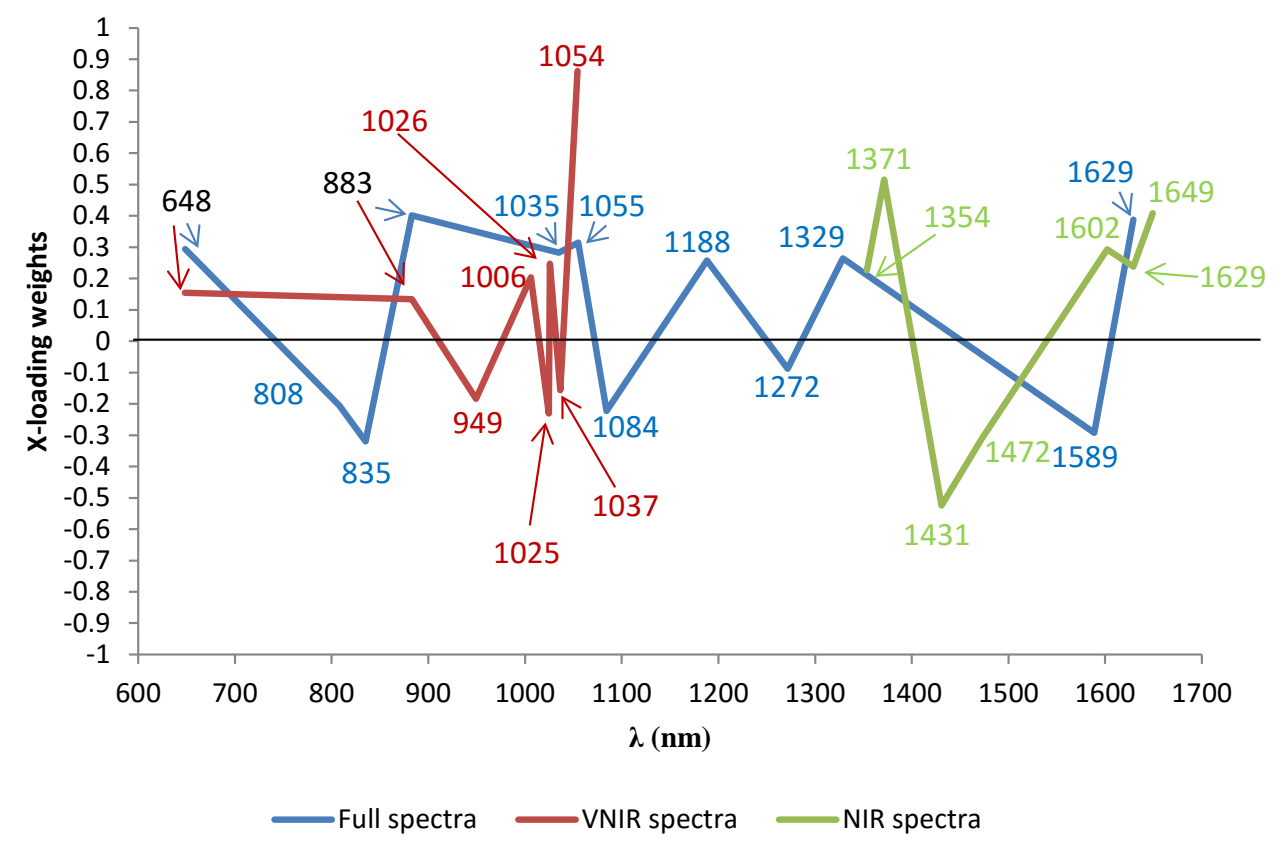

Fig. 3. The x-loading weights for the EWs selected at different spectral ranges. 
396 Figure 4 shows that all the training set and validation samples were correctly 397 classified by the best PLS-DA model obtained with eight EWs. In this situation, all 'Big Top' samples have predictive values close to 1 , thus classifying these as belonging to class ' 1 ', and 'Diamond Ray' samples have predictive values close to 0 , 400 thereby classifying these as belonging to class ' 0 '. The values of the RMSE were 401 0.179 and 0.183 for calibration and validation respectively, which exhibit good 402 agreement, thus indicating that the calibration error is a good estimation of the standard error of prediction observed in samples of the test set. Moreover, the test set yielded similar results to those of the calibration set, with $R^{2}$ of 0.872 and 0.866 respectively, which indicates a good performance of the model for varietal 406 classification.

407

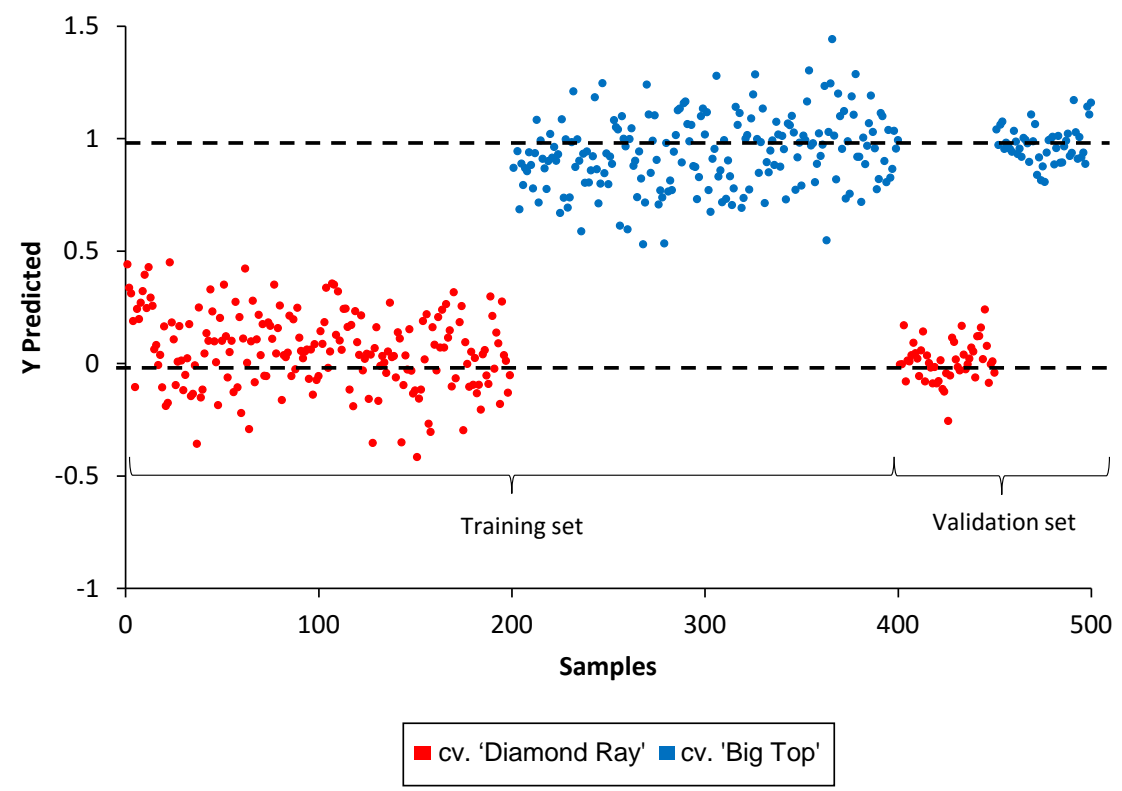

Fig. 4. Estimated class values for training and validation sets for varietal discrimination by the best PLS-DA model.

Regarding LDA, Figure 5 shows the results of the external validation by test set (20 \%) of each variety. Validation samples of the cv. 'Big Top' are displayed in blue while 
413 samples of the cv. 'Diamond Ray' are in red. There were not misclassified samples, 414 so the classification accuracy was $100 \%$ using only eight wavelengths of the VNIR 415 spectral region.
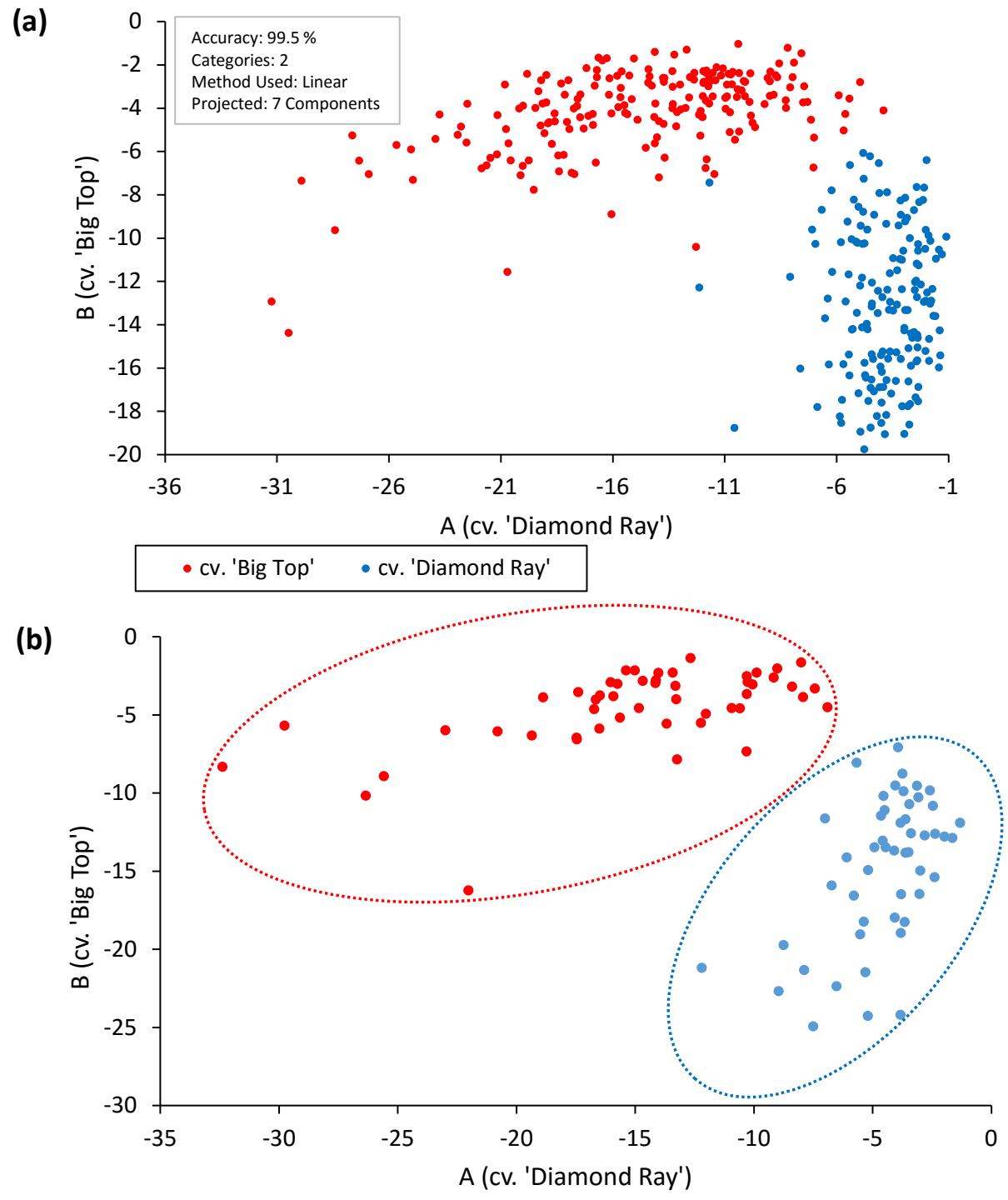

417 Fig. 5. Discrimination plot of the best LDA model for (a) the training samples and (b) the validation samples.

420 Several authors (Balabin et al., 2010; Liu et al., 2006; Sinelli et al., 2007) have 421 reported that the PLS-DA method is more effective than LDA. Indeed the LDA 422 method suffers from several limitations, for example, the number of variables cannot 
exceed the number of samples (Roggo et al., 2003) and it is not able to cope with highly collinear data, which are quite common. To overcome some limitations, over the years other techniques, in particular PLS-DA, have been devised (Marini, 2010). Similarly, to us, Long et al. (2015) combined near-infrared spectroscopy with PLS-DA for the discrimination of transgenic rice and they achieved a classification rate of 100 $\%$ in the validation test. Addicionally, a considerable effort has been made in this work towards the development of models that objectively identify variables that provide useful information and eliminate those that contain unnecessary data.

\section{CONCLUSIONS}

Classification models were developed in order to discriminate two nectarine varieties (cv. 'Big Top' and cv. 'Diamond Ray') in different spectral ranges (VNIR, NIR, and the whole spectra combined). Two classification methods including PLS-DA and LDA were evaluated based on all wavelengths or the EWs selected for the spectral regions considered. The best models were obtained using only eight EWs out of the 1838 available features of the VNIR detector, identified from the x-loading weights as the most important ones. PLS-DA and LDA models attained an accuracy of $100 \%$ for the validation set with five and seven LVs, respectively. Therefore, PLS-DA and LDA resulted as robust models for discriminating varieties of nectarine with a satisfactory level of accuracy. The comparison of the different analysis performed indicated that both detectors were able to achieve a good varietal classification, being the detector sensible in the VNIR range the one that achieved better results identifying the studied varieties of nectarines, almost identical in external and internal appearance but very different in taste and organoleptic properties.. 


\section{Acknowledgements}

449 This work was partially funded by the Generalitat Valenciana through the project

AICO/2015/122 and by the INIA and FEDER funds through projects RTA2012-00062-

C04-01 and 03. Victoria Cortés López thanks the Spanish Ministry of Education,

452

453

454

455

456

457

458

459

460

461

462

463

464

465

466

467

468

469

470

471

472

Culture and Sports for the FPU grant (FPU13/04202). The authors wish to thank the cooperative 'Fruits de Ponent' for providing the fruit.

\section{REFERENCES}

Adams, M. J., 1995. Chemometrics in Analytical Spectroscopy. Analytical Spectroscopy Monographs, p. 216.

Bachion de Santana, F., Caixeta Gontijo, L., Mitsutake, H., Júnior Mazivila, S., de Souza, L.M., Borges Neto, W., 2016. Non-destructive fraud detection in rosehip oil by MIR spectroscopy and chemometrics. Food Chemistry 209, 228-233.

Bakeev, K. A., 2010. Process Analytical Technology. United Kingdom: Wiley.

Balabin, R. M., Safieva, R. Z., Lomakina, E. I., 2010. Gasoline classification using near infrared (NIR) spectroscopy data: Comparison of multivariate techniques. Analytica Chimica Acta 671, 27-35.

Balabin, R.M., Safieva, R.Z. \& Lomakina, E.I., 2007. Comparison of linear and nonlinear calibration models based on near infrared (NIR) spectroscopy data for gasoline properties prediction. Chemometrics and Intelligent Laboratory Systems 88, 183-187.

Beebe, K.R., Pell, R.J. \& Seasholtz, M.B., 1998. Chemometrics: a Practical Guide. Wiley-Interscience, 4.

Beghi, R., Giovenzana, V., Brancadoro, L. \& Guidetti, R., 2017. Rapid evaluation of grape phytosanitary status directly at the check point station entering the winery 
by using visible/near infrared spectroscopy. Journal of Food Engineering, 204, 46-54.

Bouveresse, E., Hartmann, C., Last, I. R., Prebble, K. A., Massart, L., 1996. Standardization of Near-Infrared Spectrometric Instruments. Anal. Chem., 68, 982-990.

Bruun, S.W., Sondergaard, I., Jacobsen, S., 2007. Analysis of protein structures and interactions in complex food by Near-Infrared spectroscopy. 1. Gluten Powder. J. Agric. Food Chem. 55,7234-7243.

Cardoso, S.M \& Silva, A.M.S., 2016. Chemistry, Biology and Potential Applications of Honeybee Plant-Derived Products. Bentham Science Publishers, Sharjah, UAE.

Carr, G.L., Chubar, O., Dumas, P., 2005. Spectrochemical Analysis Using Infrared Multichannel Detectors 1st edn. (eds., Bhargava, R. \& Levin, I.W.) 56-84. Oxford: Wiley-Blackwell.

Cembalo L, Cicia G, Giudice TD, 2009. The influence of country of origin on German consumer preference for peaches: A latent class choice model. Proc. 113th Eur. Assoc. of Agricultural Economists Seminar, Chania (Greece), September 3-6, 19.

Clareton, M., 2000. Peach and nectarine production in France: trends, consumption and perspectives. Summaries Prunus breeders meeting, EMBRAPA, clima temperado Pelotas (RS), 83-91.

Commission Regulation EC, No.1861/2004 of 28 October 2004.

Cortés, V., Ortiz, C., Aleixos, N., Blasco, J., Cubero, S., Talens, P., 2016. A new internal quality index for mango and its prediction by external visible and near infrared reflection spectroscopy. Postharvest Biology and Technology, 118, 148-158. 
498 Crisosto, C., Crisosto, G., 2005. Relationship between ripe soluble solids concentration (RSSC) and consumer acceptance of high and low acid meeting flesh peach and nectarine (Prunus persica (L.) Batsch) cultivars. Postharvest Biol. Technol. 38, 239-246.

Crisosto, C.H., 2002. How do we increase peach consumption? Proceedings of 5th International Symposium on Peach, ISHS, Acta Hort. 592, 601-605.

Dragsted, L., 2008. How we can improve the consumers health through fruit consumption?. ISAFRUIT Project (www.isafruit.org).

Gelbukh, A. \& Reyes-Garcia, C. A. (November 2006). MICAI 2006: Advances in Artificial Intelligence. 5th Mexican Internacional Conference on Artificial Intelligence Apizaco, Mexico.

Gorny, J. R., Hess-Pierce, B., Kader, A. A., 1998. Effects of fruit ripeness and storage temperature on the deterioration rate of fresh-cut peach and nectarine slices. Postharvest Biology \& Technology, 33 (1), 110-113.

Guo, W., Gu, J., Liu, D., Shang, L., 2016. Peach variety identification using nearinfrared diffuse reflectance spectroscopy. Computers and Electronics in Agriculture 123, 297-303.

He, Y., Li, X. \& Deng, X., 2007. Discrimination of varieties of tea using near infrared spectroscopy by principal component analysis and BP model. Journal of Food Engineering, 79, 1238-1242.

Hernández, A., He, Y., García, A., 2006. Non-destructive measurement of acidity, soluble solids and firmness of Satsuma mandarin using Vis/NIR-spectroscopy techniques. Journal of Food Engineering 77, 313-319. 
521 Huang, H., Yu, H., Xu, H., Ying, Y., 2008. Near infrared spectroscopy for on/in-line monitoring of quality in foods and beverages: A review. Journal of Food Engineering, 87 (3), 303-313.

Iglesias, I., 2012. ¿Hacia dónde va el consumo de fruta? Análisis de los vectores que rigen su compra. Revista de Fruticultura, 28.

Iglesias, I., 2013. Peach production in Spain: Current situation and trends, from production to consumption. Preceedings of the 4th Conference, Innovation in fruit growing, Blegrade, 75-89.

Iglesias, I., Casals, E., 2014. Producción, exportación y consumo de melocotón en España. Vida Rural 373, 21-30.

Iglesias, I., Echeverría, G., 2009. Differential effect of cultivar and harvest date on nectarine colour, quality and consumer acceptance. Scientia Horticulturae, 120, 41-50.

Jha S. N., Jaiswal P., Narsaiah K., Gupta M., Bhardwaj R. \& Singh A. K., 2012. Nondestructive prediction of sweetness of intact mango using near infrared spectroscopy. Scientia Horticulturae, 138, 171 - 175.

Jha S. N., Kingsly A.R.P. \& Chopra S., 2006. Nondestructive determination of firmness and yellowness of mango during growth and storage using visual spectroscopy. Biosystems Engineering, 94(3), 397 - 402.

Jha, S. N. \& Matsuoka, T., 2004. Nondestructive determination of acid brix ratio $(A B R)$ of tomato juice using near infrared (NIR) spectroscopy. International Journal of Food Science and Technology, 39(4), 425 - 430.

Jha, S. N., Chopra, S. \& Kingsly, A. R. P., 2005. Determination of sweetness of intact mango using visual spectral analysis. Biosystems Engineering, 91(2), 157 161. 
546 Kozak, M., Scaman, C. H., 2008. Unsupervised classification methods in food sciences: discussion and outlook. Journal of the Science of Food and Agriculture, 88, 1115-1127.

Lee, J.S., Kim, S.C., Seong, K.C., Kim, C.H., Um, Y.C., Lee, S.K., 2012. Quality prediction of kiwifruit based on near infrared spectroscopy. Kor. J. Horticult. Sci. Technol. 30 (6), 709-717.

Li, J.B., Huang, W.Q., Zhao, C.J., Zhang, B.H., 2013. A comparative study for the

Li, X., He, Y., Fang, H., 2007. Non-destructive discrimination of Chinese bayberry varieties using Vis/NIR spectroscopy. Journal of Food Engineering 81, 357-363.

Li, X., Yi, S., He, S., Lv, Q., Xie, R., Zheng, Y., Deng, L., 2016. Identification of pummelo cultivars by using Vis/NIR spectra and pattern recognition methods. Precision Agric 17, 365-374.

Liu, F., He, Y. \& Wang, L., 2008. Determination of effective wavelengths for discrimination of fruit vinegars using near infrared spectroscopy and multivariate analysis. Analytica Chimica Acta 615, 10-17.

Liu, F., Jiang, Y., He, Y., 2009. Variable selection in visible/near infrared spectra for linear and nonlinear calibrations: A case study to determine soluble solids content of beer. Analytica Chimica Acta, 635, 45-52. 
570 Liu, L., Cozzolino, D., Cynkar, W. U., Gishen, M., Colby, C. B., 2006. Geographic classification of Spanish and Australian Tempranillo Red Wines by Visible and Near-Infrared Spectroscopy combined with Multivariate Analysis. J. Agric. Food Chem. 54, 6754-6759.

Liu, Y., Lyon, B.G., Windham, W.R., Realini, C.E., Pringle, T.D. \& Duckett, S., 2003. Prediction of color, texture, and sensory characteristics of beef steaks by visible and near infrared reflectance spectroscopy. A feasibility study. Meat Science $65,1107-1115$.

Liverani, A., Giovannini, D., Brandi, F., 2002. Increasing fruit quality of peaches and nectarines: the main goals of ISF-FO (Italy). Acta Horticulturae 592, 507-514.

Long, Z., Shan-shan, W., Yan-fei, D., Jia-rong, P., Cheng, Z., 2015. Discrimination of Transgenic Rice Based on Near Infrared Reflectance Spectroscopy and Partial Least Squares Regression Discriminant Analysis. Rice Science 22 (5), 245-249.

Lorente, D., Escandell-Montero, P., Cubero, S., Gómez-Sanchis, J., Blasco, J., 2015. Visible-NIR reflectance spectroscopy and manifold learning methods applied to the detection of fungal infections on citrus fruit. Journal of Food Engineering, 163, 17-21.

Lucas, A., Andueza, D., Rock, E. \& Martin, B., 2008. Prediction of Dry Matter, Fat, pH, Vitamins, Minerals, Carotenoids, Total Antioxidant Capacity, and Color in Fresh and Freee-Dried Cheeses by Visible-Near-Infrared Reflectance Spectroscopy. Journal of Agricultural and Food Chemistry 56, 6801-6808.

Marini, F., 2010. Classification Methods in Chemometrics. Current Analytical Chemistry 6, 72-79.

Martens, H., Nielsen, J. P., Engelsen, S. B., 2003. Light scattering and light absorbance separated by extended multiplicative signal correction. Application 
to near-infrared transmission analysis of powder mixtures. Anal. Chem.75, 394404.

597

598

599

600

601

602

603

604

605

606

607

608

609

610

611

612

613

614

615

616

617

618

619

Martins, P. A., Cirino de Carvalho, L., Cunha, L. C., Manhas, F., Teixeira, G. H., 2016. Robust PLS models for soluble solids content and firmness determination in low chilling peach using near infrared spectroscopy (NIR). Postharvest Biology and Technology, 111, 345-351.

McGlone, V. A., Kawano, S., 1998. Firmness, dry-matter and soluble-solids assessment of post-harvest kiwifruit by NIR spectroscopy. Postharvest Biology and Technology, 13, 131-141.

Merzlyak, M. N., Solo, A. E., Gitelson, A. A., 2003. Reflectance spectral features and non-destructive estimation of chlorophyll, carotenoid and anthocyanin content in apple fruit. Postharvest Biology and Technology, 27, 197-211.

Naes, T., Isaksson, T., Fearn, T., Davies, T., 2002. A User-friendly guide to multivariate calibration and classification. NIR Publications: Chichester, U.K.; $p$ 420.

Naes, T., Isaksson, T., Fearn, T., Davies, T., 2004. Interpreting PCR and PLS solutions. In: A User-Friendly Guide to Multivariate Calibration and Classification. Chichester, UK.

Nicolaï, B.M., Beullens, K., Bobelyn, E., Peirs, A., Saeys, W., Theron, I.K., Lammertyn, J., 2007. Non-destructive measurement of fruit and vegetable quality by means of NIR spectroscopy: a review. Postharvest Biol. Technol. 46, 99-118.

Osborne, B.G., Fearn, T., Hindle, P.H., 1993. Practical NIR Spectroscopy with Applications in Food and Beverage Analysis, 2nd ed. Longman Group, Burnt Mill, Harlow, Essex, England, UK, pp. 123-132. 
Otto, M., 1999. Chemometrics; Wiley-VCH: Hemsbach, Germany, p. 314.

Ouyang, Q., Liu, Y., Chen, Q., Zhang, Z., Zhao, J., Guo, Z. \& Gu, H., 2017. Intelligent evaluation of color sensory quality of black tea by visible-near infrared spectroscopy technology: A comparison of spectra and color data information. Sepectrochimica Acta Part A: Molecular and Biomolecular Spectroscopy 180, 91-96.

Pérez-Marín, D., Sánchez, M. T., Paz, P., González-Dugo, V., Soriano, M. A., 2011. Postharvest shelf-life discrimination of nectarines produced under different irrigation strategies using NIR-spectroscopy. Food Science and Technology, 44, 1405-1414.

Pérez-Marín, D., Sánchez, M.T., Paz, P., Soriano, M.A., Guerrero, J.E., GarridoVaro, A., 2009. Non-destructive determination of quality parameters in nectarines during on-tree ripening and postharvest storage. Postharvest Biology and Technology, 52, 180-188.

Picha, 2006. Horticultural Crop Quality Characteristics Important in International Trade. Acta Hort., 712, 423-426.

Radman, M., 2005. Consumer consumption and perception of organic products in Croatia. British Food Journal 107 (4), 263-273.

Reig, G., Iglesias, I., Gatius, F., Alegre, S., 2013. Antioxidant Capacity, Quality, and Nutrient Contents of Several Peach Cultivars [Prunus persica (L.) Batsch] grown in Spain. Journal of Agricultural and Food Chemistry 61 (26), 6344-6357.

Reita, G., Peano, C., Saranwong, S., Kawano, S., 2008. An evaluating technique for variety compatibility of fruit applied to a near infrared Birx calibration system: a case study using Brix calibration for nectarines. Journal of Near Infrared Spectroscopy, 16 (2), 83-89. 
645 Rodriguez-Campos, J., Escalona-Buendía, H. B., Orozco-Avila, I., Lugo-Cervantes, E., Jaramillo-Flores, M. E., 2011. Dynamics of volatile and non-volatile compounds in cocoa (Theobroma cacao L.) during fermentation and drying processes using principal components analysis. Food Research International, 44, 250-258.

Rodriguez-Saona, L.E., Fry, F.S., McLaughlin, A. \& Calvey, E.M., 2001. Rapid analysis of sugars in fruit juices by FT-NIR spectroscopy. Carbohydrate Research, 336, 63-74.

Roggo, Y., Duuponchel, L., Ruckebusch, C., Huvenne, J. P., 2003. Statistical tests for comparison of quantitative and qualitative models developed with near infrared spectral data. Journal of Molecular Structure 654, 253-262.

Sádecká, J., Jakubíková, M., Májek, P., Kleinová, A., 2016. Classification of plum spirit drinks by synchronous fluorescence spectroscopy. Food Chemistry 196, 783-790.

Sánchez, M. T., De la Haba, M. J., Guerrero, J. E., Garrido-Varo, A., Pérez-Marín, D., 2011. Testing of a local approach for the prediction of quality parameters in intact nectarines using a portable NIRS instrument. Postharvest Biology and Technology 60 (2), 130-135.

Shao, Y., He, Y., Gómez, A.H., Pereir, A.G., Qiu, Z., Zhang, Y., 2007. Visible/near infrared spectrometric technique for nondestructive assessment of tomato 'Heatwave' (Lycopersicumesculentum) quality characteristics. J. Food Eng. 81 (4), 672-678.

Sinelli, N., Stella Cosio, M., Gigliotty, C., Casiraghi, E., 2007. Preliminary study on application of mid infrared spectroscopy for the evaluation of the virgin olive oil "freshness". Analytica Chimica Acta 598, 128-134. 
670 Soares, S. F. C., Gomes, A. A., Galvão Filho, A. R., Araújo, M. C. U., Galvão, R. K.

671

672

673

674

675

676

677

678

679

680

681

682

683

684

685

686

687

688

689

690

691

692 H., 2013. The successive projections algorithm. Trends in Analytical Chemistry, 42, 84-98.

Suphamitmongkol, W., Nie, G.L., Liu, R., Kasemsumran, S., Shi, Y., 2013. An alternative approach for the classification of orange varieties based on near infrared spectroscopy. Comput. Electron. Agric. 91, 87-93.

Tijskens, L. M. M., Zerbini, P. E., Schouten, R. E., Vanoli, M., Jacob, S., Grassi, M., Torricelli, A., 2007. Assessing harvest maturity in nectarines. Postharvest Biology and Technology 45, 204-213.

Torres, R., Montes, E.J., Perez, O.A, Andrade, R.D., 2013. Relación del color y dele estado de madurez con las propiedades fisicoquímicas de frutas tropicales. Información Tecnológica 24 (4), 51.

UNE-ISO 12647-2:2010. Tecnología gráfica. Control del proceso para la elaboración de separaciones de color, pruebas e impresos de mediotono. Parte 2: Procesos litográficos offset.

Valero, A., Marín, S., Ramos, A. J., Sanchis, V., 2007. Effect of preharvest fungicides and interacting fungi on Aspergillus carbonarius growth and ochratoxin $A$ synthesis in dehydrating grapes. Letters in Applied Microbiology 45, 194-199.

Walsh, K.B., Golic, M., Greensill, C.V., 2004. Sorting of fruit and vegetables using near infrared spectroscopy: application to soluble solids and dry matter content. J. Near Infrared Spectrosc. 12, 141-148.

Wandel, M., Bugge, A., 1997. Environmental concern in consumer evaluation of food quality. Food Quality and Preference 8 (10), 19-26. 
693 Williams, P. C., Norris, K. H., 1987. Qualitative applications of near infrared 694 reflectance spectroscopy. In P. C. Williams \& K. H. Norris (Eds.), Near infrared 695 technology in the agricultural and food industries, 241-246.

696 Xiaobo, Z., Jiewen, Z., Povey, M.J.W., Holmes, M. \& Hanpin, M., 2010. Variables 697 selection methods in near-infrared spectroscopy. Analytica Chimica Acta 667, 698 14-32. 